\title{
Rapidly progressing and resistant warts in an immuno-competent male
}

\author{
Md. Shahidullah Sikder, Mohammed Saiful Islam Bhuiyan and Tauhida Noor
}

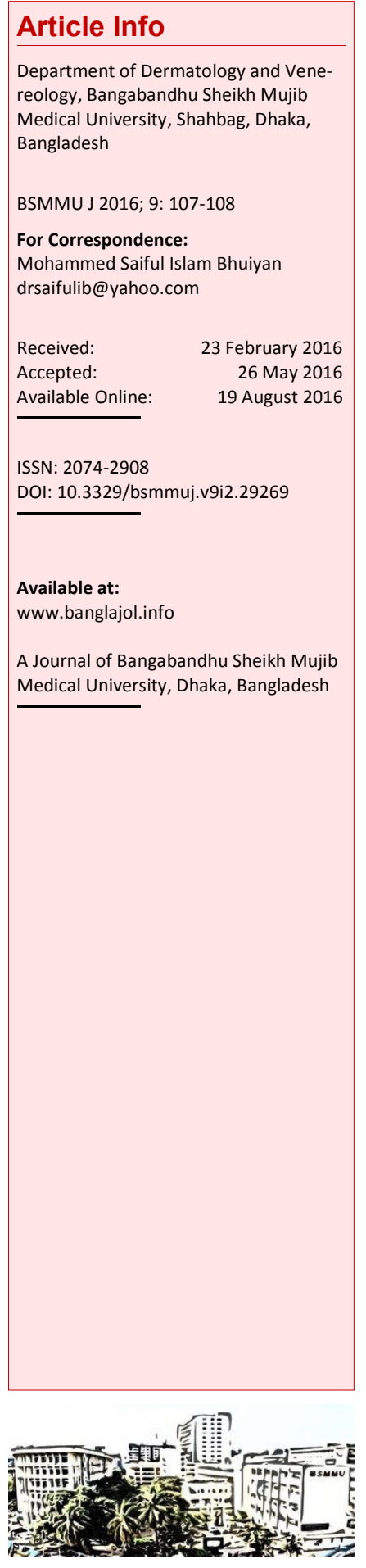

\section{Abstract}

Cutaneous warts are common skin conditions caused by different specific strains of the human papilloma virus (HPV), mostly affect children as localized lesion on the hands and feet. They are slowly progressing and disseminated lesions are found in immuno-compromised situations. Usually majority of warts disappear by few months to two years. This is a case of extensive, giant, rapidly progressing and resistant warts in an immuno-competent adult male.

\section{Introduction}

Warts are common viral skin disease caused by infection of keratinocytes by human papilloma virus (HPV). The development of epidermal thickening and hyper-keratinization occurs following infection at the basal layer and clonal proliferation, which eventually results in a visible wart, weeks or even months later.1 The clinical appearance of warts is variable and depends to some extent on the type of HPV involved and the anatomical site. HPV can also remain dormant within epithelial cells without visible disease. Any epithelial surface can be affected and different types of HPV tend to favor particular anatomical sites. $\underline{2}$ There are over 150 genotypically different types of HPV, with classification based on defined variation of the viral DNA. The majority of common warts are caused by HPV types 1, 2, 4, 27 or 57 , and plane warts by HPV types 3 or 10.1

We are presenting a rare case of extensive rapidly progressing cutaneous warts in an immunocompetent adult male.

\section{Case Report}

A 42 years old unemployed adult male from a rural area of Northern part of Bangladesh, presented with the complaints of multiple warty lesions for 2 years. The lesions started with itchy rashes over the extensors of arms and forearms, trunk and thigh that became pustular within a week followed by warty appearance. Pruritus was severe and more at night. He also noticed multiple painless nodules in left axilla, groins and neck. He had no history of trauma preceding the lesion, contact with active TB patient, fever and weight loss. His bowel and bladder habits were normal. He was a smoker and had history of contact with professional sex workers. He belonged to a lower socioeconomic condition and had no family history of such illness. He took several medications with no significant improvement.

On examination, he was anxious looking, hypo pigmented patch in lower lip, not anemic, nonicteric with normal vital parameters and generalized lymphadenopathy involving both inguinal, posterior cervical chain, left axilla; multiple in number, firm, non tender, mobile. Some were matted with normal overlying skin and largest measuring $5 \mathrm{~cm} \times 5 \mathrm{~cm}$. There were bilateral symmetrical hypopigmented well defined verrucous indurated plaques coalescing to form large plaques over the extensor surface of both arms (Figure 1) and forearms, abdomen, back and scrotum with hyperpigmentation and lichenification of the skin surrounding the lesions. Hairs and nails were normal. Other systems revealed no abnormality.

All routine blood pictures were normal including complete blood count, $\mathrm{Hb} \%$, ESR, peripheral blood film, liver function (SGOT, SGPT) and serum creatinine. HIV-1 \& 2, VDRL and Mantoux test were negative. Chest radiograph was also normal. Excisional biopsy of one axillary (left) lymph node and one skin lesion on arm (left) was done for histopathological study. On lymph node histopathology, the nodal architecture was preserved. It revealed lymphoid follicles of different size and shape with germinal centers and areas of fibrosis. Focal areas of paracortical region showed melanophages. No granuloma or malignancy was seen and overall picture supported a dermatopathic lymphadenitis. On histopathology of skin biopsy, epidermis revealed hyperkeratosis, parakeratosis with marked acanthosis and cytoplasmic vacuolization and papilloma- 


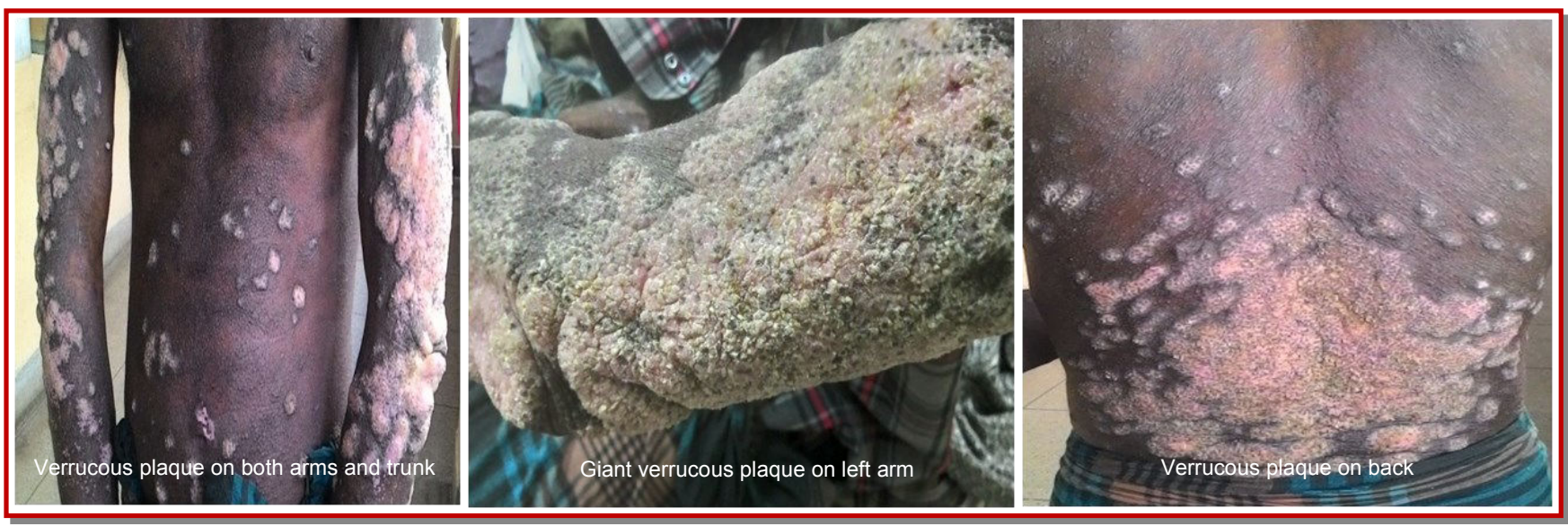

Figure 1: Verrucous plaque on both arms \& trunk (left photograph), left arm (middle one) and back (right photograph)

tosis. No granuloma or malignant cell or fungal bodies was demonstrated. Histopathologically it was compatible with verruca vulgaris.

\section{Discussion}

Cutaneous viral warts are uncommon in infancy, common in childhood, and decreasingly less common from the second decade onwards. Studies have suggested that $5-30 \%$ of children and young adults have warts. $\stackrel{3-6}{-}$

Usually, Wart won't cause any symptoms other than mild discomfort and occasional itching. Spontaneous clearance of the infection, firstly with a reduction in size of the wart and then its disappearance, can occur at any time from a few months to years later. Clearance in children can occur after only a few months, with half clear at 1 year and about two-thirds by 2 years, 7 but these previously infected individuals have a higher risk for development of new warts than those who were never infected. 8 Warts in adults can be much slower to clear, and persistence for 5-10 years is not uncommon. $\underline{1}$ However, some lesion may rapidly grow in size and number and become resistant to treatment overtime.9 Risk factors of cutaneous warts are immunosuppression, close contact with affected people, and activities such as nail biting and walking barefoot.10

\section{Conclusion}

Considering widely distributed lesion, giant size, rapid growth, persistence, involving a non-immunocompromised adult, this is a rare case of cutaneous wart.

\section{References}

1. Sterling JC, Gibbs S, Haque Hussain SS, Mustafa MF, Handfield-Jones SE. British Association of Dermatologists' Guidelines for the management of cutaneous warts 2014. Brit J Dermatol. 2014; 171: 696-712.

2. Lynch MD, Cliffe J, Morris-Jones R. Management of cutaneous viral warts. BMJ. 2014; 348: g3339.

3. Kyriakis K, Pagana G, Michailides C. Lifetime prevalence fluctuations of common and plane viral warts. J Eur Acad Dermatol Venereol. 2007; 21: 260 62.

4. Kwok CS, Gibbs S, Bennett C, Holland R, Abbott R. Topical treatments for cutaneous warts. Cochrane Database Syst Rev. 2013; 9: CD001781.

5. Kilkenny M, Merlin K, Young R, Marks R. The prevalence of common skin conditions in Australian school students: Common, plane and plantar viral warts. Br J Dermatol. 1998; 138: 840-45.

6. van Haalen FM, Bruggink SC, Gussekloo J. Assendelft WJ, Eekhof JA. Wart in primary school children: Prevalence and relation with environmental factors. Br J Dermatol. 2009; 161: 148-52.

7. Bruggink SC, Eekhof JA, Egberts PF, van Blijswijk SC, Assendelft WJ, Gussekloo J. Natural course of cutaneous warts among primary school children: A prospective cohort study. Ann Fam Med. 2013; 11: 437-41.

8. Allen AL, Siegfried EC. The natural history of condyloma in children. J Am Acad Dermatol. 1998; 39: 951-55.

9. Nucci V, Torchia D, Cappugi P. Condyloma acuminatum of the tongue treated with photodynamic therapy. Clin Infect Dis. 2009; 48: 1330-32.

10. Wolff K, Johnson RA. Fitzpatrick's Color atlas and synopsis of clinical dermatology. 6th ed. McGrawHill Medical, 2009, pp 787-94. 